\title{
3D HERITAGE RECONSTRUCTION AND SCAN-TO-HBIM-TO-XR PROJECT OF THE TOMB OF CAECILIA METELLA AND CAETANI CASTLE, ROME, ITALY
}

\author{
F. Banfi ${ }^{1 *}$, R. Brumana ${ }^{1}$, S. Roascio $^{2}$, M. Previtali ${ }^{1}$, F. Roncoroni $^{1}$, A. Mandelli $^{1}$, C. Stanga $^{1}$ \\ ${ }^{1}$ Architecture, Built environment and Construction engineering (ABC.) Department, Politecnico di Milano, Milano, Italy \\ (fabrizio.banfi; raffaella.brumana; mattia.previtali; fabio.roncoroni; chiara.stanga)@ polimi.it \\ ${ }^{2}$ Ministero della Cultura \\ Parco Archeologico dell'Appia Antica, Piazza delle Finanze 1- 00185 Roma \\ stefano.roascio@beniculturali.it
}

\section{Commission II}

KEY WORDS: HBIM (Heritage Building Information Modelling), scan-to-BIM, eXtended Reality, Virtual Museum, VR (Virtual Reality), Building Archaeology, Historical reconstruction

\begin{abstract}
:
2020 meant the loss of 41.5 million visitors for Italian museums, monuments and archaeological sites. The regions that drive tourism and the Italian museum paid the price in terms of visitors and income. In this context, virtual museums have been taking on new forms of interaction, communication and sharing of information, overshadowing traditional applications based on sharing collections through static images or simple panoramas. Virtual Reality (VR) and Augmented Reality (AR) provide the end-user with more innovative learning with the latest technological advances and digital tools. Thanks to the integration of the latest 3D modelling and digital survey techniques with the Visual Programming Language (VPL) and eXteded Reality (XR) development platforms, the authors propose a scan-to-BIM-to-XR method based on different forms of architectural representation, digital survey (terrestrial and aerial) and building archaeology able to transmit the tangible and intangible values of the different types of architectural artefacts, from the large scale (building and its urban context), medium (art collections, sculptures, museum itineraries) up to the small scale (building archaeology) of one of the most important historical buildings in the city of Rome.
\end{abstract}

\section{INTRODUCTION}

\subsection{General context}

In recent years, thanks to the development of the latest generation of digital tools, a culture of disseminating information connected to the built heritage has been developed through increasingly interactive and immersive forms. In the domain of Digital Cultural Heritage (DCH), many studies created virtual experiences that incorporate identity values and meanings both from a cultural, historical and architectural point of view. In particular, eXtended Reality (XR), Augmented and Virtual Reality (AR-VR) are playing a decisive role in increasing communication, interactivity and immersion for different types of users, from construction sector experts to students and virtual tourists (Ioannides et al., 2017).

As a result, numerous museums and art galleries offer virtual tours of their collections through devices such as VR headsets, web interfaces, panoramic tours and serious games. As is well known, thanks to well-established methods based on Heritage Building Information Modeling, TLS-MMS survey, and digital photogrammetry (Aerial and Terrestrial), it is possible to obtain informative representation capable of supporting different types of analysis, from building archaeology to more advanced studies, passing from interactive forms of as-found, as-designed and asbuilt models to support the preservation process of the historical assets (Banfi, 2021). In this context, experts in the construction sector realised the added value of integrating disciplines such as architectural representation, geomatics, archaeology and restoration with information technology. For those reasons, thanks to the collaboration between the Ministry of Culture Appia Antica Archaeological Park - and the Politecnico di Milano ABCLab Gicarus it was possible to investigate the forms of digital representation capable of increasing the paradigms of interactivity, immersion and interoperability by using a broad spectrum of digital data. In particular, thanks to the integration of multi-data sources from 3D surveys with advanced forms of digital models, it was possible to implement a virtual experience of the Tomb of Caecilia Metella and the Caetani Castle in Rome. The following study proposes a scan-to-HBIM-to-XR project capable of bringing the reality of the built heritage, its tangible and intangible values, to virtual users, investigating novel forms of interactivity and immersion to support the site visit, increasing the level of information and interoperability between HBIM models and the latest generation forms of XR.

\subsection{The crisis of museums during the pandemic and the digital response}

The traditional forms of museums that we all know have many advantages, including engaging and educating the community and fostering an informal learning process. Individuals acquire attitudes, values, skills, and knowledge starting from daily experience and their environment. On the other hand, the

\footnotetext{
* Fabrizio Banfi fabrizio.banfi@polimi.it
} 
collections of art, sculptures, works, and paintings are decontextualized, adapted, and forced into a new environment, consequently losing its real context's historical and cultural background. Furthermore, tourists must respect the safety distances imposed by the global health emergency and the flow rates, favouring a sustainable use of the premises. 2020 meant the loss of 41.5 million visitors to Italian museums, monuments and archaeological sites and over 19 million paying visitors, which means 190 million euros gross of lost revenues. The regions that drive tourism and the Italian museums paid the price in terms of visitors and income. Lazio lost $80.7 \%$ of visitors compared to 2019. Tuscany, a region in which Florence stands out with its Uffizi, over $75 \%$. Campania 69\%. Figure 1 shows visitors (paying and non-paying) and gross revenue by region for the past 4 years. By choosing the metric to analyse, the size of the squares represents the value (Infodata, Il Sole 24 Ore, 2021). The legend at the top right explains the totals.

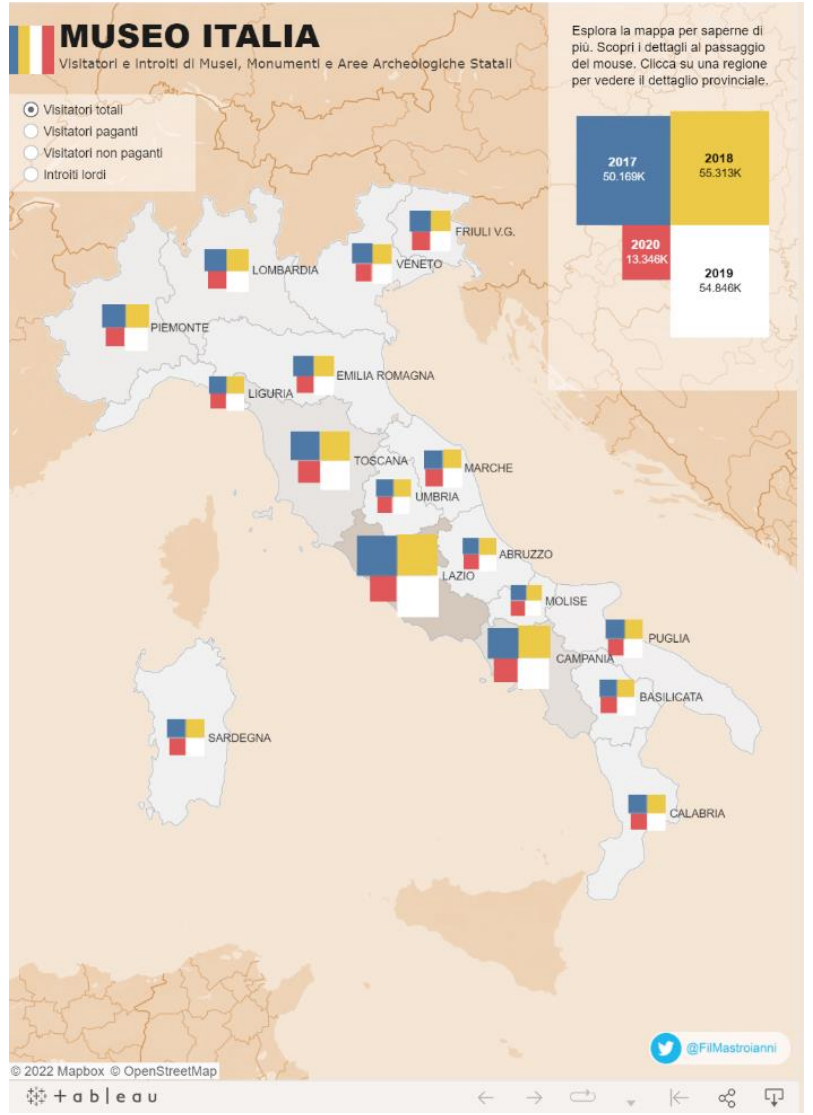

Figure 1. Visitors and income from museums, monuments and state archaeological sites. Source: Il Sole 24 Ore (https://www.infodata.ilsole24ore.com/2021/05/23/la-crisi-deimusei-della-cultura-la-pandemia-raccontata-tre-grafici/)

Figure 2 shows the situation relating to Lazio, both in terms of the number of visitors and the gross concerning the years 2017 , 2018, 2020 and 2021. The most important collapse comes, as always, from the most dizzying heights. Rome, its museums and its archaeological sites lose over 19 million visitors. The Pantheon, a Roman icon of the Pigna district, saw the guests it gathered within its walls descend from 9.3 million in 2019 to just 1.7 million in the last year. The most significant losses come from Italy's most visited Archaeological Circuit, including the Colosseum, Roman Forum, and Palatine Hill. 6.3 million lost visitors, of which 5.2 million paying visitors, for a total of 47.7 million euros gross of lost revenue, moving from almost 55 million visitors in 2019 to just 13 million in 2020. This is the photograph generated by a pandemic year, which has also brought Italian museums to their knees. Numbers translate into large sums of missed collections, which went from over 242 million to just 52 million in the last year, with a loss of $78.4 \%$ (Infodata, Il Sole 24 Ore, 2021).

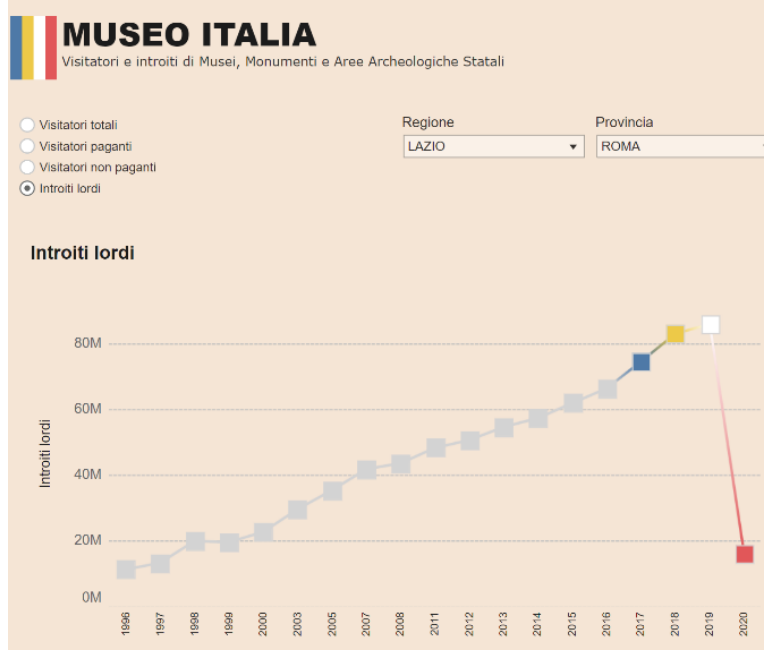

Figure 2. Visitors and income from museums, monuments and state archaeological sites: gross income from the Lazio region, the Province of Rome. Source: il Sole 24 Ore (https://www.infodata.ilsole24ore.com/2021/05/23/la-crisi-deimusei-della-cultura-la-pandemia-raccontata-tre-grafici/)

On the other hand, the recent form of the virtual museum does not allow for high levels of interactivity between the user and the museum itself. Forms of VR-AR are not yet fully integrated into the museum as they require high skills in multiple disciplinary and application sectors such as computer graphics, computer programming, digital representation using advanced modelling, restoration and archaeology. The process of creating a model aimed at representing a historic building that must be protected, restored and described in different digital forms poses a significant challenge to scientific research. Different disciplines, technologies and tools must be addressed to obtain a series of digital products representing it. Consequently, the values of geometry, measurement, materials, historical information and related analyses must be integrated and connected to digital models capable of accommodating a large amount of heterogeneous information and data.

In this context, the 3D survey, the scan-to-BIM process and the most advanced forms of heritage building information modelling (HBIM) allow passing from a traditional 2D CAD information logic to digital twins capable of responding to different needs during the life cycle, such as the protection of the artifact, its restoration, and its digital story. As is well known, many studies have shown how HBIM and the scan-to-BIM process can exponentially improve different types of analysis, from finite element analysis to construction site management and scheduled maintenance (Brumana et al., 2021). In this context, the digital architectural representation, the scan-to-BIM process, and the $3 \mathrm{D}$ survey have benefited from IT developments that are decisive in the automation and creation of digital models.

Many software developers such as Autodesk, Bentley and Graphisoft have developed new features and improved software interfaces for the direct management of point clouds and highresolution orthophotos (primary 3D survey outputs). 
Digital photogrammetry has also made it possible to improve and complete the data coming from the scans and provide professionals with reliable bases from a geometric and metric point of view and useful for the generation of intelligent models. Furthermore, thanks to the advent of drones at affordable prices, professionals can now independently use aerial photogrammetric data, thus having the opportunity to see parts of buildings that are not reachable or inaccessible.

The challenge, therefore, lies in transforming a large amount of data such as point clouds, 2D CAD vector drawings and textured mesh models into informative models. Then, it is necessary to orient the $3 \mathrm{D}$ models to the latest generation of devices capable of collecting, sharing, communicating and telling the tangible and intangible values of the artefact. This transformation process (geometric models into informative models) opens up new possibilities for HBIM models. Before the models were used for purely professional purposes in the construction sector. It is now possible to expand the circle of use even to non-experts such as virtual tourists and students.

Thanks to new levels of interoperability and development platforms, it is possible to convert and transfer models in VR and AR environments, thus creating new interactive and immersive experiences such as serious games, virtual museums and the most advanced forms of extended reality. However, how to transform this large amount of data, passing from simple points without information (3D scans, point clouds ) and static objects (mesh and HBIM models) to interactive virtual objects (IVOs) and new forms of VR-AR and virtual museums is a step not yet deepened. For these reasons, this study proposes the creation of XR environments able to accompany the visit of the real museum trying to outline a scan-to-BIM-to-XR method capable of exponentially increasing the knowledge and dissemination of historical and cultural information, renewing the interest in the works of art and increasing the curiosity of the visit through novel interactive experiences (Figure 3).

\section{Data Collection}

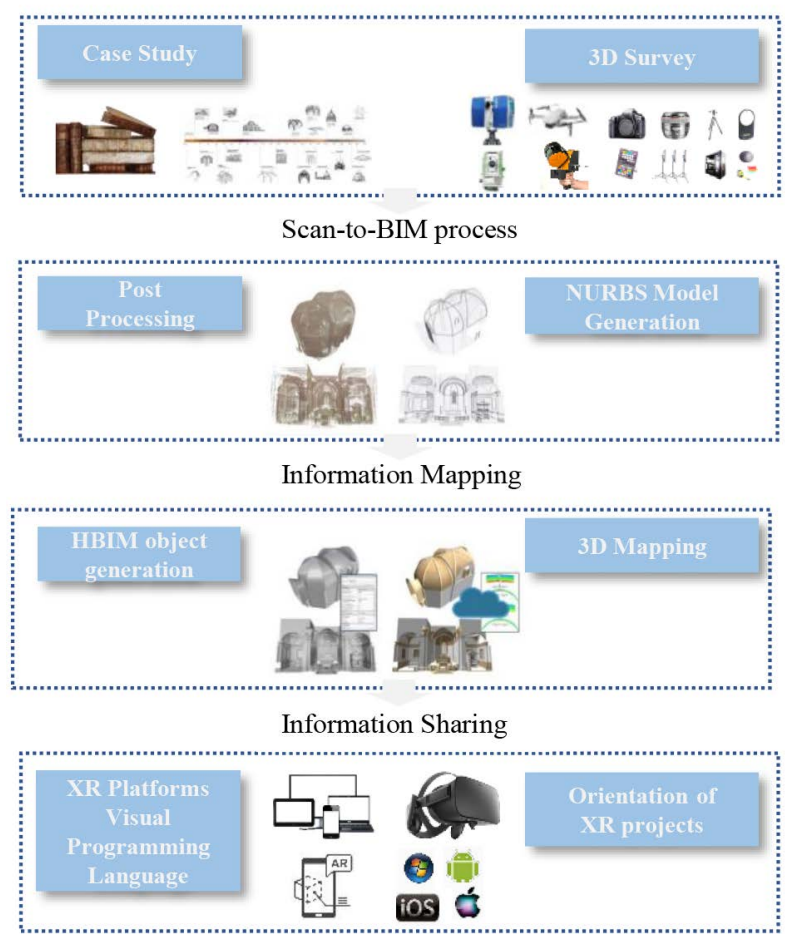

2. THE TOMB OF CAECILIA METELLA AND CAETANI CASTEL, ROME, ITALY: FROM 3D SURVEY TO ARCHITECTURAL RAPRESENTATION

2.1 The research case study: historical and cultural background of Caecilia Metella and Caetani Castel.

The presence of the mausoleum of Cecilia Metella, one of the most significant structures of classicism, has, over the centuries, negatively affected the reading of the medieval settlement that stands next to it. Little or scarce attention was paid to the medieval palace complex (Roascio, 2021). This contribution aims to highlight the evidence of the medieval building and partially restore the past appearance of this noble residence, inexorably erased by the passing of time (Figure 4). Before directly addressing the medieval palace's structures, it is necessary to address the historical, cultural, and strategic assumptions that led to the construction of the articulated settlement of the Caetani on the Via Appia. When in March 1302, Cardinal Francesco Caetani moved with conviction to secure control of a large portion of the Roman Campagna south of the city, the family's ambitions were clear. Benedetto Caetani, the future Pope Boniface VIII, was the figure who influenced the family's fate in the last 25 years of the thirteenth century. The Caetani, indeed, from obscure provincial nobility, quickly rises to the highest rank of the Church. The stages that lead the Caetani family to conquer the most influential power in the Middle Ages are relatively fast. In 1281, Benedetto Caetani was appointed Cardinal (Carocci, 1999). This fact shifts the family's center of gravity from southern Lazio and its main town, Anagni, to the city of Rome. Through the conspicuous economic revenues of the office of the cardinalate and an unscrupulous and aggressive policy, the Caetani took possession of several estates and castles (Selvamolle, Ninfa, Norma, to name the most significant) and progressively expanded their sphere of influence from Southern Lazio to the city of Rome (Carocci, 1993a).
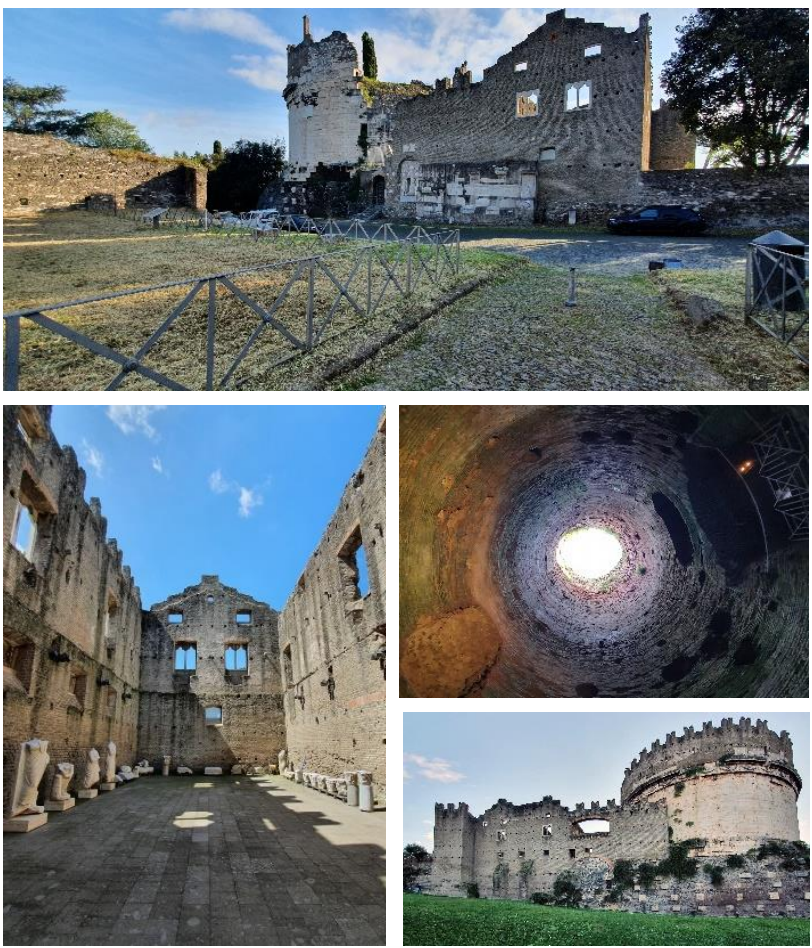

Figure 3.The proposed research process.

Figure 4. The research case study. 
However, the event certainly destined to make a substantial change in the family's fortunes is the election of Benedetto as Roman pontiff, with the name of Boniface VIII (1294). Rome, however, was not an open and accessible field at the end of the thirteenth century; the power was, in fact, firmly in the hands of the powerful Colonna family and its allies. Therefore, it was necessary to defeat all the Colonna first to control the city entirely. The war is waged in 1297 . The sources outline a real papal crusade against the seats of the Colonna, with the use of mercenary armies that cost the pope an impressive 600,000 florins. The results were not long in coming, and one by one, the Colonna strongholds fell into the hands of the Caetani troops, that did not hesitate to raze and sprinkle the most significant enemy squares with salt, as happened in the ancient Colonna di Palestrina palace (Carocci, 1999). Once the Colonna family had been defeated, the Caetani could finally organise their settlement in Rome with a genuine display of power. Between the end of the thirteenth century and the early years of the fourteenth century, the powerful nephews of Pope Boniface VIII were particularly active in acquiring or building valuable fortified residences. It is not by chance that Dante attacked this pope for simony and nepotism. However, it is easy to believe that the direction of these acquisitions remained firmly in the hands of the authoritative pontiff. In the very last years of 1200 , his nephew Pietro Caetani acquired the Torre delle Milizie in the center of Rome (Carocci, 1993b); the structural changes and adjustments of the mighty tower are due precisely to Boniface VIII, in the early 1300s. In this period, the desire to count on great and prestigious structures, but also militarily defended, seems to be a widespread need for the most influential Roman baronial and cardinalate families. The Caetani family is no exception (Carocci \& Giannini, 2021). In this precise historical and geopolitical framework from March 1302 to May of the following year, Cardinal Francesco Caetani completed the acquisition of extensive land in the Capo di Bove area, on the Appia, and completed much of the settlement. On 12 May 1303, Pope Boniface VIII itself consecrated the Church of S. Nicola (Esposito \& Passigli 2008), probably not yet wholly completed, while the palace residence and the extensive turreted wall enclosing a section of the ancient road consular were terminated at the time. The powerful Cardinal Francesco, once again under the direction of his uncle Boniface VIII, in just over a year completed the acquisition of 600 hectares of agricultural land (Esposito \& Passigli 2008), built a wall of 2 hectares with 19 towers, raised the prestigious baronial palace and founded an elegant church in Gothic style. The Roman mausoleum was reused as a fortified keep, enhancing the defensive value of an imposing structure. Nevertheless, above all, they took possession of a prestigious structure from the Roman age to underline the symbolic value of the new acquisition of the Caetani, who thus declared themselves heirs of one of the most symbolic monuments of the classical city (Figure 5).

The extensive acquisition of land and the foundation of such a complex settlement, which merges military functions with other residential and representative functions, hides many other ambitions from the family and the pope. The intention is clearly to establish a territorial lordship (Carocci, 2004) on the outskirts of Rome and on the Appia, which was the primary connection between the possessions of the Caetani in southern Lazio and Rome itself. As it happened with the Milizie tower in the city center, the family-controlled Rome and its countryside.

The extensive walls were probably designed to build a so-called "villa nova," a fortified village to provide accommodation for the peasants of the vast estate and organise and control them.

The Church of S. Nicola has been endowed with parochial rights (Rinaldi, 2014) allow the authors to understand how the enclosure should have contained a high number of residents in the founders' intentions.
However, the Caetani's dream of glory was shattered with the untimely death of the pope in 1303, after the famous and hard battle (the so-called "slap of Anagni") with the king of France. For this reason, the Church was probably not completed, and the fortified enclosure was occupied minimally. However, only an archaeological excavation could verify whether the Caetani village took hold or aborted from its earliest stages.
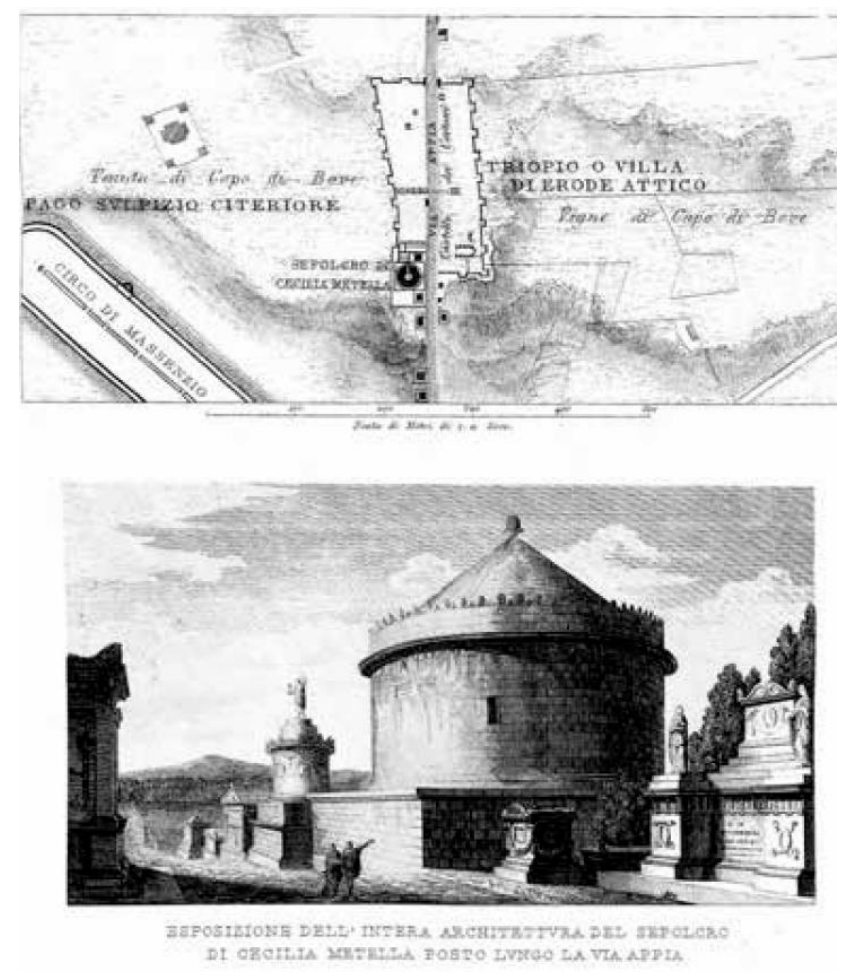

Figure 5. The research case study and the Appian way. Source: Luigi Canina 1853, tav. XVI.

\subsection{The 3D survey: laser scanning and digital photogrammetry (terrestrial and aerial)}

The geometrical 3D survey of the Tomb of Caecilia Metella was subdivided into two different surveying campaigns: the first one, carried out in May 2021, was aimed at measuring a local geodetic network, performing a static TLS survey of the Tomb and producing orthophotos for the main façade of the Tomb and the inner hall; the second one performed in November 2021 completed the first campaign with some context information acquired with a mobile mapping system, and overall orthophoto of the site and an orthophoto of the tower derived from a UAV survey. Due to the need of a stable reference system to connect the different surveys strategies (static and mobile scanning, terrestrial and aerial photogrammetry) a geodetic network was established within the Tomb and in its surroundings. The materialisation of the benchmark was carried out by using a set of retroreflective targets in the main areas of the Tomb: entrance, inner hall and underground "Lava room". The retroreflective targets were located, in correspondence of stable points, to allow Total Station repositioning with resection strategy.

The materialised geodetic network was measured with Leica TPS1200 total station. The network was compensated by leastsquares adjustment providing an average precision of about \pm 1.5 $\mathrm{mm}$ on the benchmarks. The registration of the scans was performed by using a target-based approach. In addition to targets used for scan-to-scan registration 20 targets were measured with the Total Station with an average precision on targets of about 
$\pm 2.0 \mathrm{~mm}$. In addition, about 80 points were measured as Ground Control Points and Check Points for the photogrammetric project. A static TLS survey was carried out by using a Faro Focus 3D X130.

The 37 scans acquired for the Tomb were registered, as previously mentioned, with a target-based strategy with an average precision of the targets of $\pm 3.0 \mathrm{~mm}$ (Figure 6).

Eventually, a set of photogrammetric acquisitions were made for the walls of the inner hall, the Tomb façade and of the underground "Lava room".

Those projects aimed to generate orthophotos of the different surveyed areas and the generation of textured models to be used both for 2D drawing and 3D modelling.
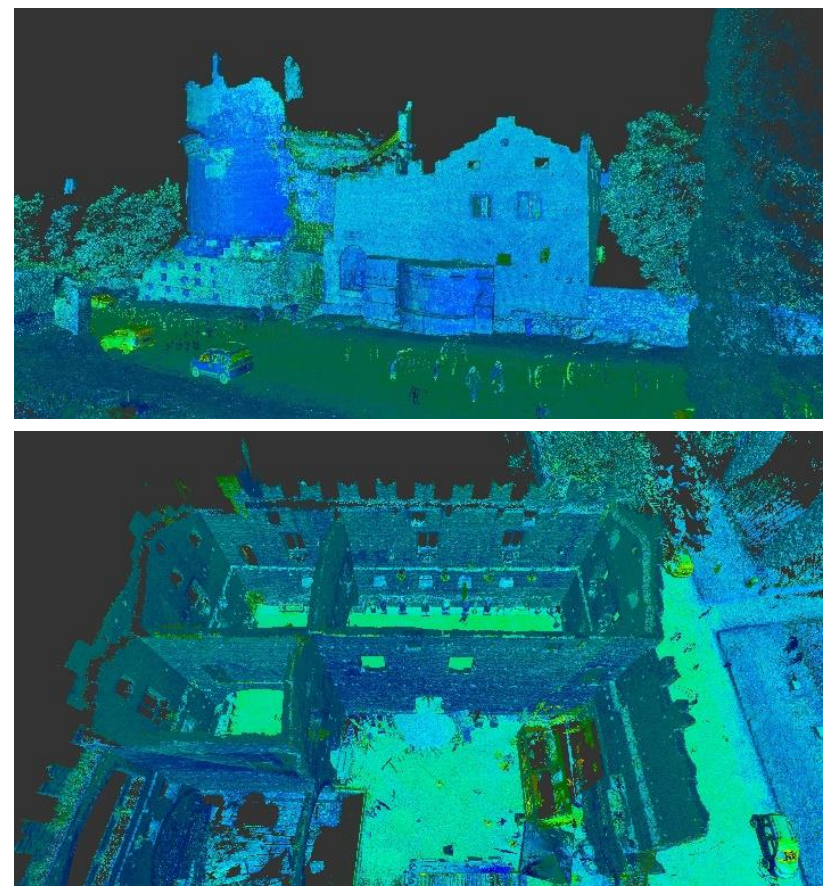

Figure 6. TLS survey data (Top Main Façade, bottom Caetani Castle).

The terrestrial surveys were followed by an aerial photogrammetric 3D survey to integrate the data. Some portions of the Caecilia Metella complex, such as the upper part of the walls and the top part of the tower, are not directly accessible.

As widely discussed, the use of not expensive and lightweight Unmanned Aerial Systems (UAS) let speed up the photogrammetric surveys, tough preserving the accuracy of measurements typical of the architectonical field. For these reasons, it was decided to employ a DJI Mavic Mini 2 to complete the geometrical survey started with TLS and terrestrial photogrammetry. Moreover, an Unmanned Aerial Vehicle permitted a privileged point of view of some portions not visible from the ground (Figure 7). Some additional images were acquired to document the state of conservation and the decay of the walls. According to the Italian Law, flights were performed: even if the Cecilia Metella complex is near the Ciampino Airport, the building falls in an area where the flight is not prohibited. The procedure required to get the permission of flight from the competent Authority and the maximum height of $25 \mathrm{~m}$ from the take-off point had to be respected. The dataset comprises 492 images acquired at the maximum resolution $(4.000 * 3.000$ pixels $)$ at a mean distance of 10 meters from the walls. Given the dimension of the sensor equal to $1 / 2,3$ ", it is possible to calculate a mean Ground Sample Distance (GSD) of $5 \mathrm{~mm}$. The images were acquired automatically, shooting every 2 seconds during three different flights. The first flight interested the walls of the circular tower, the second one, with the camera tilted downwards, recorded the "floors" of the complex and the last one was used to link the previous two. At the end of the UAS survey, a mobile mapping acquisition was performed using the ZEB Horizon. This survey aimed to link the previous TLS acquisition with the new aerial photogrammetric surveys. The high-density point clouds from the mobile system can be aligned with the previous surveys with a cloud-to-cloud approach. At the same time, the ZEB survey acquired the position of the aerial targets, and the coordinates are then imposed in the photogrammetric project. These elaborations will lead surely to a loss of accuracy, but the values obtained are still in the range of the architectonic field.
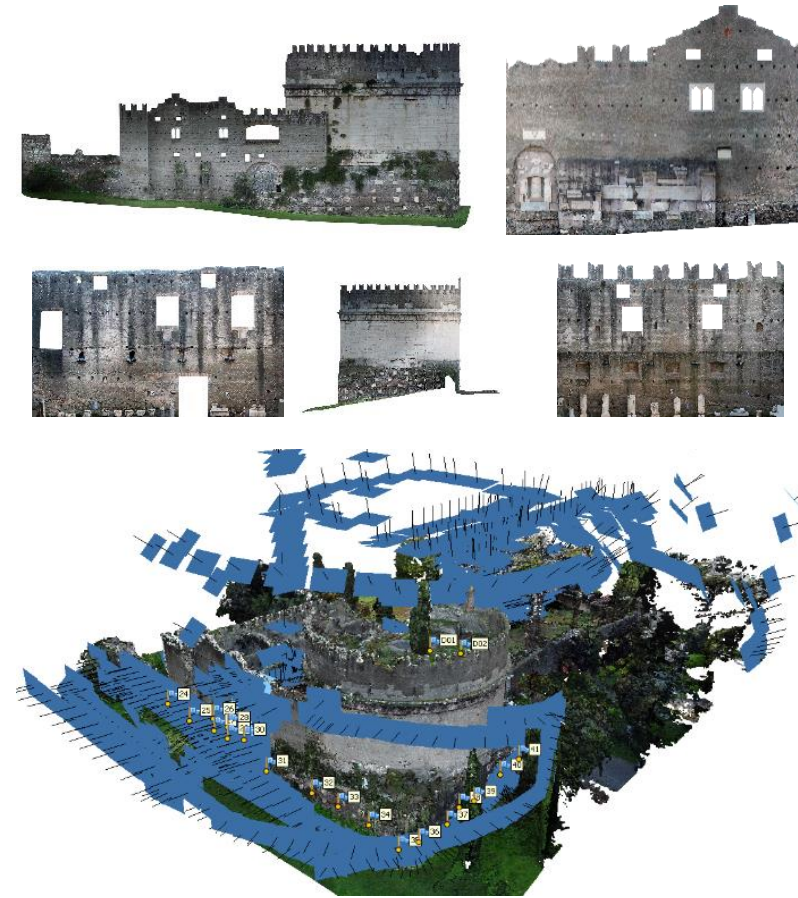

Figure 7. Aerial photogrammetric outputs (orthophotos and point clouds).

\subsection{The architectural representation, building archaeology, digital drawing and the scan-to-BIM process}

From an architectural point of view, the building is characterised by a very particular choice. It has already been pointed out that the facades with a pediment ending in steps respond to the socalled Staffelgiebel building typology, common in centralnorthern France. In Rome, significantly, there are two buildings attributable to Francesco Caetani that employ this termination of the front: this one in Capo di Bove and the palace of S. Maria in Cosmedin, the Church of which Francesco was a cardinal. Probably this particular and non-local choice is used as a distinctive sign of a rapidly growing aristocratic family (Carrocci \& Giannini 2021; Rinaldi, 2014). It remains to determine the genesis of this particular stylistic choice in the Roman context; Rinaldi believes that Francesco's numerous priories in France (York, Paris, Arras, Lisieux, Laon) influenced the client's choices. That is undoubtedly a possibility, even though it is not to be ruled out the chance - perhaps more remarkable - that this Francophone language results from the strong contacts between the Caetani family and the Angevin Kingdom of Naples. Roffredo II, brother of the pope, obtained the County of Caserta from Charles II of Anjou in the second half of the 13th century, and many contacts are documented between the family and the Angevin area (Pistilli, 2015). It is even hypothesised that an 
architect from the Neapolitan Angevin circle designed the Church of S. Nicola (Rinaldi, 2014). Even the particular northern French-style palatial choice and the walled castrum itself seem comparable to some foundations of Charles of Anjou in southern Italy (Pistilli, 2015). In Capo di Bove some architects of French origin, coming from the construction sites of the Kingdom of Naples, or in any case, a personality who had formed at the court of Anjou may have worked directly.

The building has long since lost the roofs and internal horizontals at a structural level, but reading the wall elevations and some comparisons allow the authors to reconstruct at least hypothetically the original appearance.

The conformation of the building with an elongated rectangular or "L-shaped" body, on two floors, with mullioned windows on the main floor, seems to be one of the recurring features of the palaces founded by the Caetani between the second half of the 13th and the beginning of the 14th century. Another recurring aspect is the presence of robust round arches on the ground floor, supporting the wooden floors. Similar preparations are present in Fondi, Sermoneta, Ninfa, but also at the Bonifacio palace in Anagni.

The large Bonifacian hall of the Fondi palace, built by the greatgrandson of Pope Roffredo III, probably offers the most accurate comparisons for Capo di Bove. This hall was the central place of representation, government, and ostentation of power (the palace's great hall on the Appia measures over 156 square meters). As regards the internal spatial organisation, comparisons with the other existing buildings indicate that the ground floor was intended for warehouses, while in the upper noble floor, there was always an ample principal room, often painted, also known as the "room of the barons" (Pistilli, 2015). Also, in this case, the main floor has a double register of openings with mullioned windows with a seat at floor level and smaller windows under the trusses (Figure 8). This double order of windows, also in Capo di Bove, had led to think of an additional attic floor. The three-dimensional modelling of the building helped to rule out this hypothesis. Regarding the openings, the elegant trefoil mullioned windows find an identical correspondence with those of the Caetani fortress in Ninfa, built in the same period and, it seems, by the same architect who worked on the Appian Way.
The reconstruction of the interior finishes, of which this contribution is anticipation, poses many problems. The presence of the fireplaces is evident from the traces of a plant in the large living room and a second one in what must have been the main bedroom, ample space of 78.50 square meters. The large fireplace in the living room must have had an imposing rounded hood on lithic shelves (the footprints are still found on the wall). It has a precise comparison in the contemporary Caetani castle of Ninfa. Viollet le Duc demonstrates that such monumental fireplaces were very common in French constructions: one from a noble residence in Cluny is very similar (Viollet Le Duc, 2002). The walls of the principal room must have been at least partially frescoed: evident traces of frescoes are preserved in the two open niches on the south façade. The internal walls are decorated with a red border and floral racemes. In the center, there is an archaic majolica mug with the typical pelican beak, produced in the Roman-Viterbo area in the first half of the 14th century (Ricci, 2010a).

In the second niche, a jug with a cylindrical, almost vertical neck and pourer appears to be an even older form (Ricci, 2010b) and testifies how the frescoes are probably of the original layout. Further pieces of the fresco are preserved on the jambs and the lintel of the door that connects the living room to the bedroom. Also, in this case, it has red borders on a white background and floral racemes. Unfortunately, the early collapse of the roof caused a widespread washout of the wall surfaces, and the frescoes are preserved to a minimum, only where there is protection. In addition to the surviving traces, the pictorial decoration of the Caetani palace in Fondi once again offers an excellent comparison: in fact, frames with floral friezes on a white field are found, enclosed by red bands, which run in the upper part of the walls (Savelli, 2013). Most likely, a similar finish was also present in the building. The frescoes were not supposed to be the only decoration on the walls. In all the rooms on the main floor (about 320 square meters in total), a horizontal level of stone shelves protruding from the wall arranged at about $2.35 \mathrm{~m}$ from the floor level. The small dimensions of the shelves $(8 \times 13 \mathrm{~cm}$ with a protrusion of about $17 \mathrm{~cm})$ do not allow the authors to hypothesise a structural function, as also clarified by the simulations on the 3D model (Figure 9).
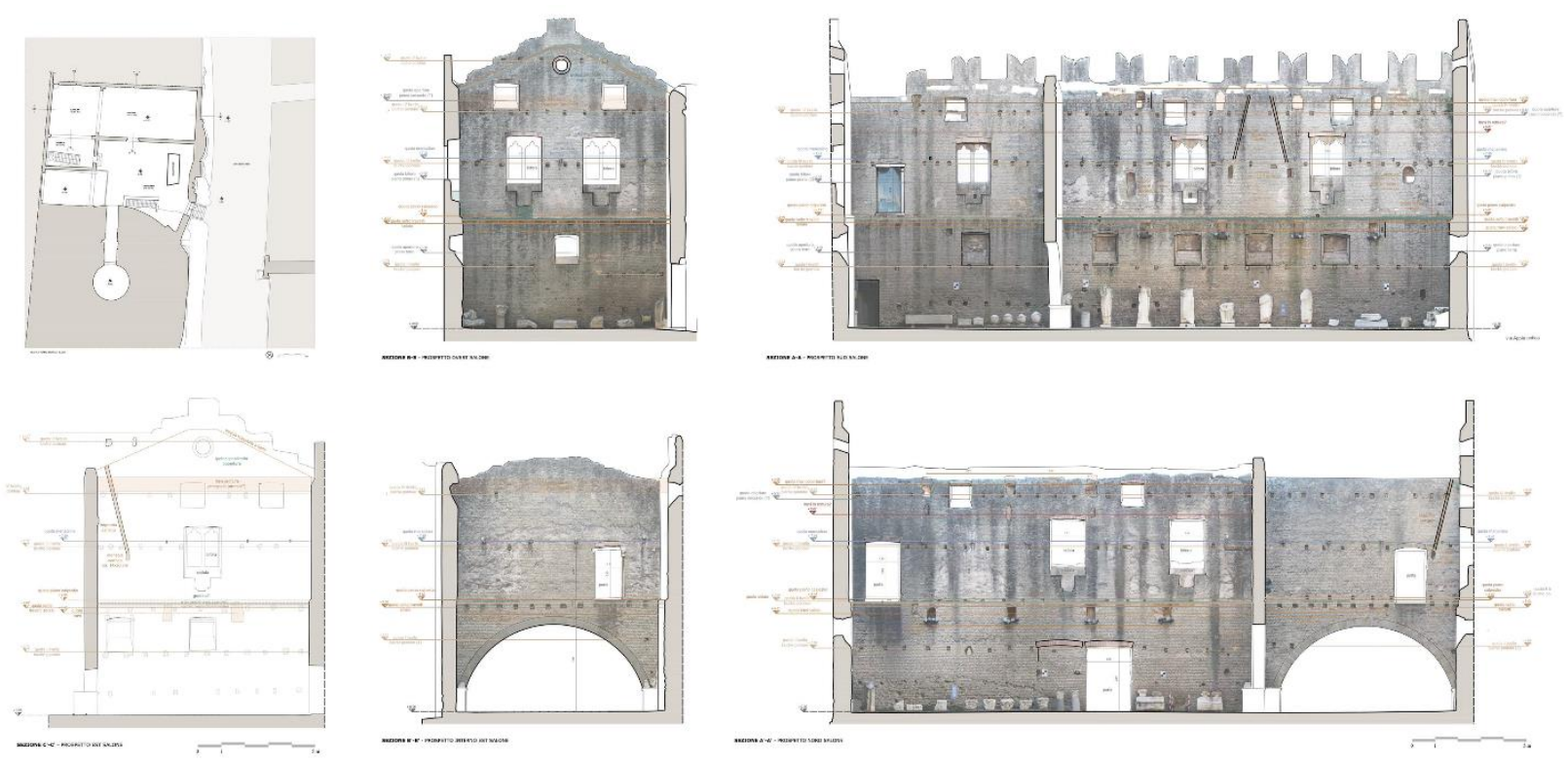

Figure 8. As-found 2D CAD Drawings and Building archaeology analysis. 
Most likely, they are runners on which cloth drapes were hung. The use of tapestries and fabrics that covered the walls is a very common element in medieval architecture, with a function that is decorative and insulating. The iconographic comparisons are manifold, for example, in Florence in the Church of Ognissanti, where colourful veils decorate the lower part of the walls (Benati, 1995). For the use of hanging decorated veils higher up, as in our case, see the Supper of Abbot Guido, portrayed at the Abbey of Pomposa by Pietro da Rimini in the first half of the fourteenth century. A stick with eyelets supports a fabric that runs $2 / 3$ of the height of the wall can also be seen in a work by Cristoforo da Bologna, also from the fourteenth century (Benati, 1995). The positioning line of the shelves intersects the mullioned windows at half-height; this means that the drapes could also serve as a kind of curtain and that they completely covered, if necessary, the frescoed wall cabinets. Finally, the 3D survey carried out with a precise mapping of the wall surfaces by a drone made it possible to acquire new data for the outside. On the sizeable north-eastern front of the building, below the arches that support the shelf of the large arched window, traces of reddish plaster can be seen. This data is significant and allow the authors to hypothesise that the external elevations were also covered by painted plaster. Traces of plaster are found in several points on the same wall, but the substantial washout has cancelled the pictorial film, which instead was saved, protected under the arches. The investigations carried out and those in progress, together with the modelling of the building structure, make it possible to study this prestigious architecture more accurately. They contribute above all to reconstructing the original appearance of the building, which must have been much more prosperous than it appears to our eyes today.
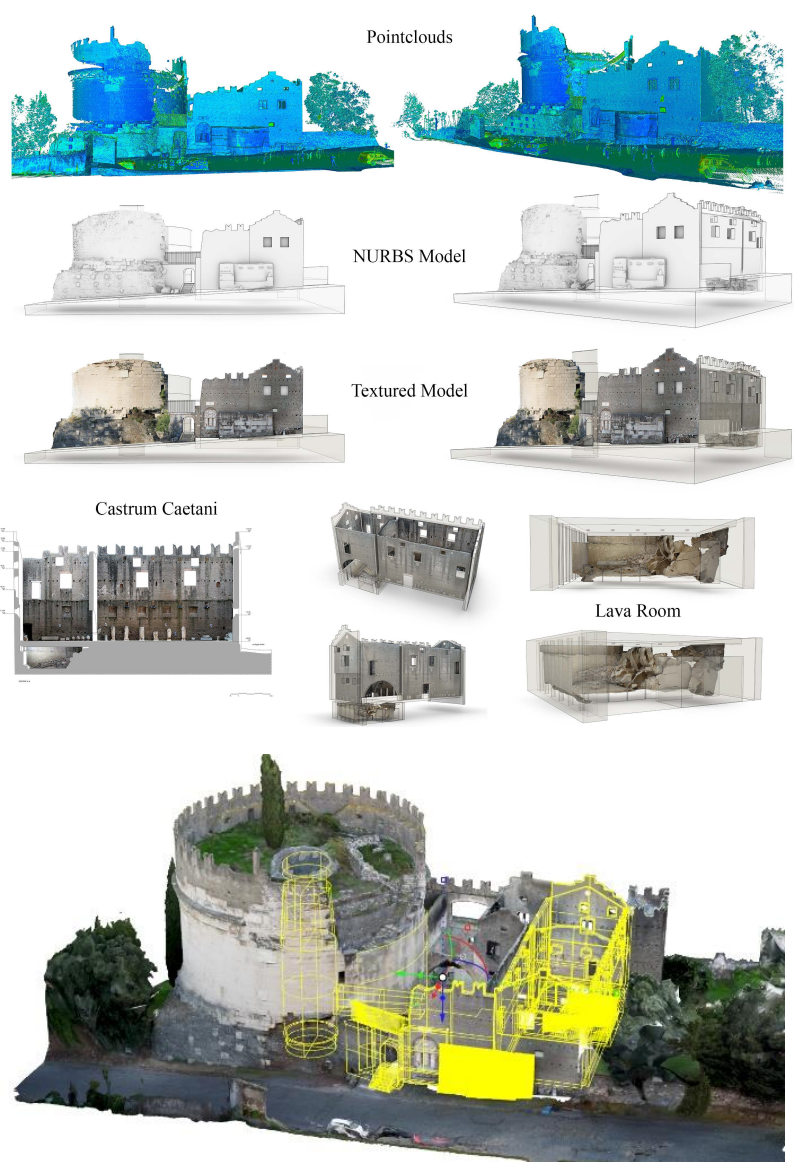

Figure 9. The Scan-to-BIM process applied to the research case study.

\section{THE EXTENDED REALITY PROJECT OF THE TOMB OF CAECILIA METELLA AND CAETANI CASTEL,}

The historical reconstruction has required the management and processing of a large amount of data from the 3D survey, 2D-3D architectural representation, studies and material analyses. In particular, thanks to the latest generation survey techniques, it was possible to obtain (i) photogrammetric models capable of including terrestrial and aerial data, (ii) orthophotos and highresolution textures useful for the production of (iii) as-found drawings and (iv) point clouds from TLS and (v) MMS. Those types of data, defined as primary data sources, have been verified, interpreted and analysed for the next phase: creating an immersive environment oriented to a digital interactive experience. In this context, 3D drawing and digital modelling based on NURBS algorithms have allowed the authors to go beyond a simple 3D representation. Thanks to NURBS algorithms based on the interpolation of point clouds it was possible to manage the paradigm of complexity in metric and geometric terms. On the other hand, the growing need to transfer historical and cultural information within the HBIM model has allowed the authors to direct the model generation process to open platforms for developing XR projects. Thanks to the latest developments in the field of gaming, computer science and visual programming language (VPL), it was possible to move from a static model composed of different categories of 3D objects (mesh, NURBS and HBIM objects) to a digital environment capable of interacting directly with the virtual user (Figure 10).

The key factors in creating the interactive environment capable of accommodating both the model corresponding to the detected reality and the historical reconstruction deriving from the studies carried out were:

(i) the automatic synchronisation of model environments with the open platforms for the implementation of the project XR;

(ii) the use of VPL for the development of specific blueprints (Unreal Engine visual scripting) able to give life to static objects and information;

(iii) the accurate interactive virtual objects (IVOs).

The advantages found for each key factor are:

(i) the synchronization of more software has allowed reducing exponentially the creation of an immersive environment. In particular, it was possible to model and at the same time create the interactive experience without having to close and save the models each time as they were created. The automatic synchronization has allowed the real-time synchronization of the NURBS and HBIM models made in MC Neel Rhinoceros and Autodesk Revit directly with Twinmotion and Unreal Engine;

(ii) the VPL has made it possible to develop blueprints capable of responding to user input through various devices such as workstations, laptops, tablets, mobile phones and VR headsets. Traditional computer programming languages do not allow architects, archaeologists and museum curators to develop XR environments. Thanks to the VPL programming logic it was possible to develop XR experiences without having advanced computer knowledge, reaching an adequate level for the historical reconstruction of the case study;

(iii) the different types of IVOs have been created to increase the levels of immersion and interactivity. They are oriented to the specific needs of the virtual museums, the sharing of its contents and the historical reconstruction of the Caetani Castle, thus highlighting elements that a traditional visit would not provide. 

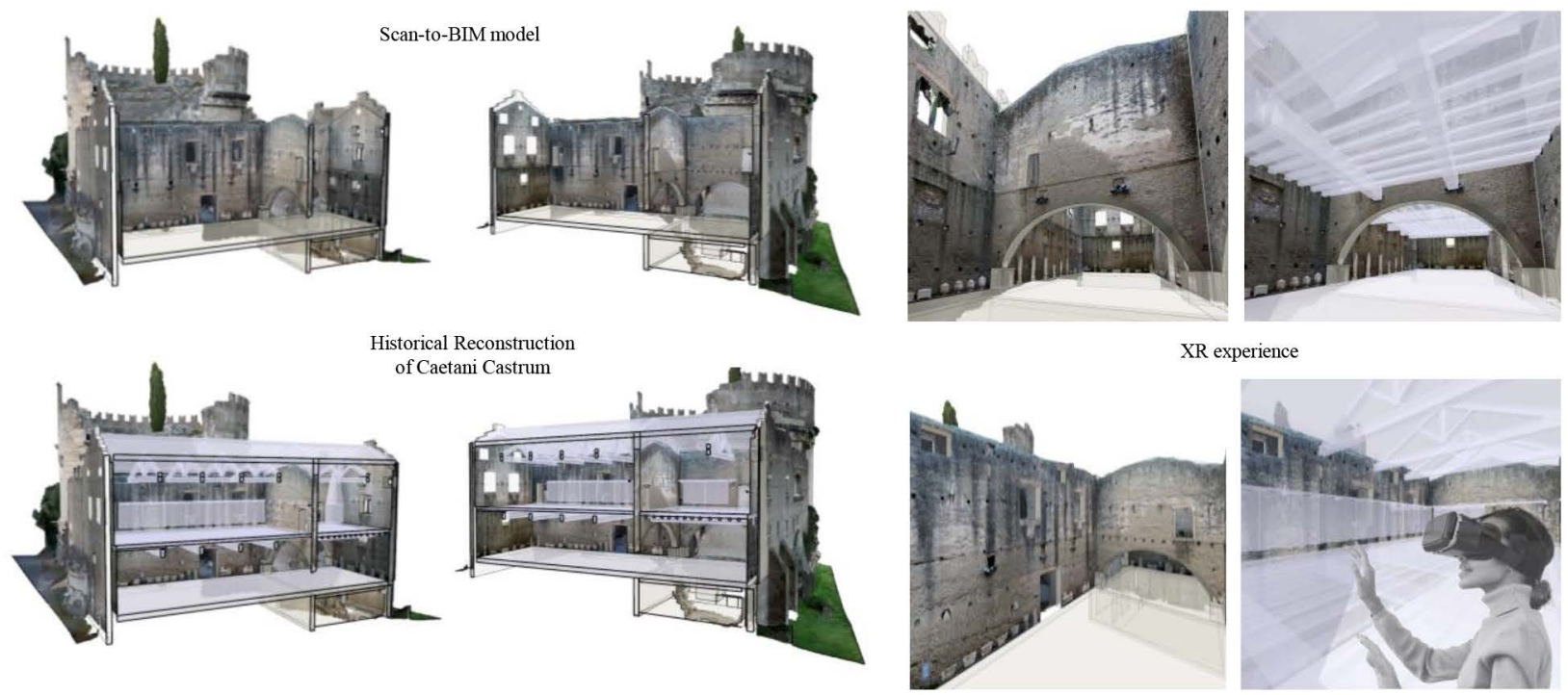

Figure 10. The Scan-to-BIM model, the historical reconstruction and XR experience of Caecilia Metella and Caetani Castrum.

\section{CONCLUSION}

Italian museums, monuments and archaeological sites need novel forms of virtual museums, interaction, communication and sharing of information to face the pandemic era. Thanks to the integration of the latest 3D modelling and digital survey techniques with the visual programming language (VPL) and extended reality (XR) development platforms, it has been possible to define a scan-to-BIM-to-XR method based on different forms of architectural representation, digital survey (terrestrial and aerial) and building archaeology of one of the most important historical buildings in the city of Rome. The XR project of the mausoleum of Caecilia metella and Caetani Castle improved the levels of immersion and interactivity of a virtual experience aimed at narrating the historical reconstruction. In particular, interactive virtual objects (IVOs) and XR development platforms and VR have defined a digital process based on the latest generation tools to increase and disseminate content in new digital forms.

\section{ACKNOWLEDGEMENTS}

The authors thanks to the Director of the Appia Antica Archaeological Park, architect Simone Quilici, who followed and encouraged this study and our work on the Appian Way.

\section{REFERENCES}

Banfi, F. (2021). The Evolution of Interactivity, Immersion and Interoperability in HBIM: Digital Model Uses, VR and AR for Built Cultural Heritage. ISPRS International Journal of Geo-Information, 10(10), 685.

Benati D. (1995), Pittura murale in Italia. Dal tardo Duecento ai primi del Quattrocento, a cura di M. Gregori (ed.), Bergamo, pp. 46-61.

Brumana, R., Stanga, C., \& Banfi, F. (2021). Models and scales for quality control: toward the definition of specifications (GOA-LOG) for the generation and re-use of HBIM object libraries in a Common Data Environment. Applied Geomatics, 1-29.

Carocci S. (1993a), Baroni di Roma. Dominazioni signorili e lignaggi aristocratici nel Duecento.

Carocci S. (1993b), Baroni in città: considerazioni sull'insediamento e i diritti urbani della grande nobiltà, in Hubert E. (ed.), Roma nei secoli XIII e XIV: cinque saggi (Collection de l'École française de Rome), pp. 139-173.
Carocci S. (1999), Il nepotismo nel medioevo. Papi, cardinali e famiglie nobili. Roma.

Carocci S. (2004), I Caetani e le altre famiglie baronali del Lazio alla fine del Duecento e nella prima metà del Trecento: tipologie dei poteri signorili, in R. Cerocchi (ed.), Bonifacio VIII, i Caetani e la storia del Lazio, Roma, pp. 117131.

Carocci S., Giannini N. (2021), Portici, palazzi, torri e fortezze. Edilizia e famiglie aristocratiche a Roma (XII-XIV secolo), in «Studia historica, Historia medieval», 39 (1), pp. 7-44, https://doi.org/10.14201/shhme2021391744.

Esposito D, Passigli S. (2008), Alcune note sull'insediamento fortificato di Capodibove. Dal casale, al castrum, al casale, in A. Mazzon (ed.), Scritti per Isa. Raccolta di studi offerti a Isa Lori Sanfilippo, Roma, pp. 369-393.

Infodata Il Sole 24 Ore, https://www.infodata.ilsole24ore.com/2021/05/23/lacrisi-dei-musei-della-cultura-la-pandemia-raccontata-tre-grafici/ (December 2021).

Ioannides, M., Magnenat-Thalmann, N., \& Papagiannakis, G. (Eds.). (2017). Mixed reality and gamification for cultural heritage (Vol. 2). Berlin: Springer.

Pistilli P. F. (2015), A Meridione dell'Urbe. Il palazzo comitale nei feudi Caetani agli inizi del Trecento, “Opus Incertum", 1 , pp. 8-15. https://doi.org/10.13128/opus-18605

Ricci M. (2010), Le maioliche arcaiche, in M. Ricci, L. Vendittelli (eds.), Museo Nazionale Romano- Crypta Balbi. Ceramiche medievali e moderne, I, Roma, pp. 102-177.

Ricci M. (2010b), Ceramiche da mensa invetriate, in M. Ricci, L. Vendittelli (eds.), Museo Nazionale Romano- Crypta Balbi. Ceramiche medievali e moderne, I, Roma, pp. 31-38.

Rinaldi M. R. (2014), Il Castrum Caetani sulla via Appia. Architettura e storia di una residenza baronale, in M. Righetti (ed.), Una strada nel Medioevo. La via Appia da Roma a Terracina, Roma, pp. 31-42.

Roascio S. (2021), Il palinsesto materiale del complesso monumentale di Cecilia Metella/Castrum Caetani. Storia delle trasformazioni attraverso le fonti figurative, in Picchione A., Roascio S., Sgarbozza I, (eds.), Misurare la Terra. Un'epigrafe napoleonica dai Musei Vaticani al Mausoleo di Cecilia Metella, Roma, pp. 49-64.

Savelli F. (2013), Ricerche preliminari per uno studio sulle pitture del Palazzo Caetani, in G. Pesiri, P. F. Pistilli (eds.), Il Palazzo Caetani a Fondi. Cantiere di studi, Roma, pp. 193-210.

Viollet le Duc E. (rist. 2002), Encyclopedie Medievale, Tome I: Architecture, Tours. 